\title{
UTILITY OWNERSHIP OF COMBINED HEAT AND POWER: AN ECONOMIC MODEL BASED APPROACH
}

\author{
M. Malguarnera', A. Razban ${ }^{2}$ \\ ${ }^{1}$ M. Malguarnera is with Indiana Municipal utility, Indianapolis, IN, USA \\ (e-mail: michael.malguarnera@gmail.com) \\ ${ }^{2}$ A.Razban is with Mechanical Eng. Dept., Indiana University Purdue University(IUPUI), Indianapolis, IN, USA
}

(e-mail: arazban@iupui.edu)

\begin{abstract}
This paper proposes, and reviews, an Excel based model to evaluate the cost effectiveness for utility ownership of Combined Heat and Power (CHP) plants. CHP plants provide highly efficient use of fuel for production of electric power and useful heat. This efficient use of fuel can lead to lower energy bills for a company, or group of companies, utilizing a CHP plant, though at a large upfront cost. In order to provide the needed capital, cash reserves or debt can be used. This large capital experiments leads to longer payback periods, which may make CHP plant unattractive investments for end users, but fits perfectly into Electric power utilities investment strategy. This model was developed as a tool for an electric utility to determine if an investment into a CHP plant and selling the waste heat to an end user, would be an attractive investment worthy of further engineering investigation.

For this paper, simulations where ran at seven different power hubs in five different power markets in the United States. Overall, the model showed that CHP plant would be an attractive investment in the New York City region and Boston regions, but not in Midwest. These differences are driven by lower power and lower capacity prices in the Midwest compared to the North East.
\end{abstract}

Key Words: combined heat and power, economic approach, energy, modelling, simulation, Waste Heat

\section{INTRODUCTION}

Cogeneration, commonly referred to as Combined Heat and Power (CHP), plants have been a popular subject for academic and policy papers over the last twenty years. Their efficient use of fuel for the production of both electricity and heat make them attractive economic additions to numerous facilities including manufacturing plants, hospitals, and universities.

CHP plants provide a potential solution to many problems facing these industries, including rising fuel prices, emissions reductions, prices swings, and energy efficiency [1]. Based on technical information, and the desire to lower $\mathrm{CO} 2$ emissions, United States and European Union have made a call for more combined heat and power plants to be installed.

Historically, CHP plants have been used in many different industries, including steel, aluminum, paper, oil distillation. Within these industries, CHP plants have normally been larger (25MWThremal) and utilize waste fuels, including coke oven gas, blast furnace gas, and refinery gas. With these heavy industries, the economics of CHP plants makes them attractive, even necessary, investments for the owner of the factory.

Due to changing regulatory and economic circumstances over the last 25 years, industries without waste fuels have begun to investigate CHP implementation. Ferrara and Lange provide a thorough history of CHP growth from 1990 to present times [2].
The repeal of the fuel use act in 1987, coupled with falling price of natural gas and associated emission benefits, allowed many new CHP plants burning natural gas to be installed in the last twenty five years [3]. Many of the newer systems are topping cycles, with a prime mover, either a gas turbine or reciprocating internal combustion engine and a heat recovery system (versus the bottoming cycle with a the boiler combining electric generation and heat production). Looking solely at technical aspects of generation, CHP systems provide efficient use of fuel for electrical and thermal properties. With regard to the economics, while the variable costs are normally very favorable, the large upfront capital costs of CHP systems can make companies shy away from installation. Table 1, taken from the U.S. EPA's Catalog of CHP Technologies [4], shows the estimated 2014 costs for ten different CHP plants, these are the same plants are used in this model. For comparison, the units were analyzed at the Hudson Valley $G$ zone of NYISO with shift 1 and shift 2 operations. The unit was assumed to be paid for with a 10 year loan at $5 \%$.

Comparing solely variable cost to end users prices, or even the cost of wholesale market power, the economics of CHP facilities are almost always favorable. With capital and O\&M cost incorporated, payback may not fit into a corporate payback structure. Common practice for many companies is to only approve project with a two year or less payback; most CHP plants the payback is much longer. Additionally, the payback economics depend on the utility rate structure and the split between demand and energy charges. A potential option to avoid the corporate payback issue is utility ownership of 
the CHP plants, with the heat being sold to end users. This paper analysis the economics of utility ownership, and proposes a model to compare the cost of ownership to market forwards purchases.

Electric Power Utilities normally use long term payback periods when building new generation assets, even being required to depreciate steam units over a 20-28 year time period [5]. The model was develop as a method for a utility to compare the ownership of CHP versus purchasing market forwards for their respective service area.As such, the model looks at monthly average costs and does not analyze the dispatch of CHP plants, which would be based on incremental heat rates and site specific conditions; for more information on CHP economic dispatching, please refer to Guo, Henwood, \& von Oojien [6]. The forward markets are a result of the creation and spread of power markets in the United States. These markets have resulted in new generation projects being compared to the current and future power prices, which is why it was used as a baseline for this paper. Future prices provide a realistic, stable baseline that incorporates existing and potential new generation into the model. More importantly, they provide a practical financial comparison for investment purposes. An alternative method would be to compared the cost of a CHP plant to acquiring a traditional generation resources (coal plants, gas turbine combined cycle, etc.). The comparison of traditional plants would require there to be a need for new generation, and prices for these plants can be very hard to pinpoint due to location and design variations. Additionally, most of the traditional plants are well above the size of combined heat and power plant assumed for this model, which considers plants in the $1 \mathrm{MW}-50 \mathrm{MW}$ electric output range.

\section{BACKGROUND}

Energy markets in the United States vary greatly state to state and region to region. Therefore, in order to have a workable model, assumptions need to be outline and made.

There are two important portions of power markets, capacity and demand. Capacity is the available generation resources to meet a customer's load. Power providers need to have enough generation to meet their anticipated peak, plus an extra margin, normal $15-20 \%$, to account for forced generation outages. Some of the power markets in the United States require self-supply, others offer a market for capacity, normally measured in MW-day, and some offer a hybrid approach [7].

The second component of power price is the energy cost, and is normally based on a dispatch curve. In MISO (Midcontinent Independent System Operator, Inc.) and PJM Interconnectionfor example, each day generation operators submit offer costs in \$/MWh to provide power. The costs are based on the marginal cost of power that is the cost of fuel and consumables to produce the next MWh. These bids are submitted to the market operators, which in turn use algorithms utilizing load information, transmission lines, and expected outages to award Day Ahead Power prices.
Instantaneous variations in load are handled though real time energy market which uses current load levels and optimizes for the minimum price. Both of these calculations are done for thousands of nodes in each market. For this paper, as it was looking at futures, only uses hub prices, which are a conglomerate of many geographical nodes. Market prices were retrieved from SNL.com, which gathers information from OTC Holdings.

Future power and gas prices are reported on a monthly basis, extending out seven years. Future power prices are broken into two components, on peak and off peak hours. MISO defines On-Peak Hours as the hours between 06:00 and 22:00 EST Monday through Friday, and Off-Peak as any other hours during the week. [8] Peak power times, as the name implies, represent times of higher demand, to business being open and people being awake. Additionally, there is a strong correlation between prevailing weather and power demand, with summer and winter energy and demand being much higher than the shoulder seasons of spring and fall.

\section{MODEL}

As this model is as a planning tool, assumptions were made to allow for quicker calculations. Assumptions for the model can be split into three categories: End user, CHP operations, and energy markets. Overall, the model uses a monthly outlook and should allow planners to decide if it would be worthwhile to look into the finer operational details, including outage costs, lost production, and real time dispatch.

\section{A. End user Assumption}

1. Heat production source, most likely from a boiler, would provide any needed variably in heat load as well as provide heatwhile maintenance was being performed.

This coupled with assumptions 2 and 8 allows the unit to be on at full load while operating, simplifying the model. This allows the use of an average heat rate since model looks at power prices on a monthly basis, which are an average of the hourly peak or non-peak power prices.

2. This models assumed that the CHP is designed to provide the base load or less of the needed heat. This avoids the complication of trying to optimize the system for heat and electric production. 
TABLE 1

CHP plants 2014 installed cost from U.S. EPA's Catalog of CHP Technologies. Test Case used 10 year forwards (which took the six year forward and extrapolated them at $2 \%$ a year) and calculated the average 10 year return on investment (margin/total yearly spend). All of the dollars were discounted to 2014 dollars with an inflation rate of $2 \%$ and a discount rate of 5\% [4]

\begin{tabular}{|c|c|c|c|c|c|}
\hline \multicolumn{6}{|c|}{ Reciprocating Internal Combustion Engines } \\
\hline Installed Costs & $\begin{array}{c}\text { Tecogen Inverde } \\
\text { Ultra } 100 \\
\end{array}$ & \begin{tabular}{|c} 
GE Jenbacher JMS- \\
312 C65 \\
\end{tabular} & $\begin{array}{c}\text { GE Jenbacher JMS- } \\
416 B 85 \\
\end{array}$ & $\begin{array}{c}\text { GE Jenbacher JMS- } \\
620 F 01 \\
\end{array}$ & $\begin{array}{l}\text { Wartsilia } \\
\text { 20V34SG }\end{array}$ \\
\hline Installed Electirc Capcity (kW) & 100 & 633 & 1,121 & 3,326 & 9,341 \\
\hline Recovered Heat (mmBtu/hr) & 0.67 & 2.78 & 4.32 & 10.67 & 26.81 \\
\hline Installed Costs (2014) & $\$ 290,000$ & $\$ 1,797,087$ & $\$ 2,652,286$ & $\$ 8,697,490$ & $\$ 13,385,653$ \\
\hline $\begin{array}{l}\text { Test Case Ten Year Return on } \\
\text { Investment }\end{array}$ & $-35 \%$ & $-31 \%$ & $-21 \%$ & $-23 \%$ & $18 \%$ \\
\hline 10 Year NPV & $(98,976.00)$ & $(494,587.33)$ & $(514,153.15)$ & $(1,690,304.69)$ & $2,558,300.53$ \\
\hline \multicolumn{6}{|c|}{ Gas Turbines } \\
\hline Installed Costs & $\begin{array}{l}\text { Solar Turbine } \\
\text { Centaur } 40\end{array}$ & Solar Taurus 70 & Solar Mars100 & Solar Titam 250 & GE LM600 \\
\hline Installed Electirc Capcity (kW) & 3,304 & 7,038 & 9,950 & 20,336 & 44,488 \\
\hline Recovered Heat (mmBtu/hr) & 19.66 & 34.44 & 52.36 & 77.82 & 138.72 \\
\hline Installed Costs (2014) & $\$ 10,839,800$ & $\$ 13,867,100$ & $\$ 19,231,500$ & $\$ 33,525,900$ & $\$ 53,203,110$ \\
\hline $\begin{array}{c}\text { Test Case Ten Year Return on } \\
\text { Investment }\end{array}$ & $-40 \%$ & $-14 \%$ & $-14 \%$ & $1 \%$ & $20 \%$ \\
\hline 10 Year NPV & $(3,862,400.78)$ & $(2,039,135.79)$ & $(3,013,268.74)$ & $344,080.07$ & $13,427,828.70$ \\
\hline
\end{tabular}

The optimization of heat and power load is cover in An Algorithm for Combined Heat and Power Economic Dispatch [6]. Since this model is looking at future, which approximate monthly averages, it was felt that the micro hour-by-hour approach to this level would be inappropriate.

3. Natural gas is supplied in sufficient quantities to the end user, and a CHP plant could be supplied with the same line. No gas line upgrades are needed, as this would add additional capital costs.

4. The end user is willing to purchase the heat from the CHP on an MMBtu basis. CHP plants can provide the heat portion in many different ways, including hot water, steam, and heat from the exhaust gases. Due the many different methods and possibilities of energy delivery, this model just uses MMBtu as a standard unit.

5. CHP plant would be installed on an adjacent piece of land, or a sub plot of the end users land. This minimizes the need to run additional steam/hot water pipes, gas pipes, and electric wiring.

6. End user already has, or would install, an interconnection to the local distribution level to handle the facilities full load. This will allow the CHP plant a cheaper interconnection. In reality these costs could be split between the end user and the utility, but for this model, it was not incorporated.

7. End user's facility is capable of three shift operations. The model asks if the plant needs one, two, three shift, and weekend operations. Shift one and two correspond to peak hour pricing; shift three and weekend continuation of shifts correspond to off peak hour pricing.

8. End user purchases usable waste heat as a percentage of the cost of natural gas. In order for an end user to be interested in a CHP system on their site, especially when they do not own the CHP, there needs to be an economic incentive. 9. End user uses waste heat as a 1:1 replacement for natural gas. This means that the end user sees waste heat as they would natural gas and would have the same conversion efficiency.

\section{B. CHP Assumption}

10. CHP would burn natural gas in either a gas turbine or a reciprocating internal combustion engine (RICE). These units are off the shelf units with known pricing, maintenance, and operations. Further information on the differences in these system can be found in Catalog of CHP Technologies [4]

11. CHP maintenance is based on run hours, which allows for assigning a maintenance cost in \$/MWh. Most reciprocating internal combustion engines, maintenance cycles are solely based on run times. For gas turbines, maintenance can be based on either run time (creep issues) or starts (fatigue issues).

12. CHP plant would only operate at its rated full load output, not varying its load while operating. Since the model looks at future models that only report monthly prices, it would not make sense to chase the unit up and done. While dispatching is normally is done on marginal costs, this model is looking at average costs compared to forward prices.

13. Natural Gas is purchased in future strips. With assumption 10 in mind, natural gas would be bought on future strips, as the usage would be known. This removes the fuel part of the fuel violate of the model. For most natural gas fired electric generation, gas is purchased on a day ahead basis. Utilities determine when to buy gas when the price of gas times the marginal heat rate would be lower than the local price of power, and the marginal would be enough to cover the startup costs.

14. Unit Preforms at ISO Rated conditions year round. This assumes that there is no temperature and efficiency detrition due to higher temperatures and elevations

\section{Energy Market}

15. Hub prices are represented of the energy price at the enduser facility. Since hub prices are an indicative of prices in different areas for the respective market, the prices could be higher or lower where the CHP plant is located. Higher 
energy prices would make the CHP plant more favorable and lower prices would make it less favorable.

16. Capacity prices for years that have yet to be determined. As mentioned later, capacity prices have a huge effect on a positive or negative outcome of the model. That being said, capacity prices are a major issue of discussion in energy markets. PJM provides a three year look ahead, while MISO only does a year look ahead, and ERCOT (Electric Reliability Council of Texas) does not have a capacity market. These prices, as discussed below, can have a large effect on the net cost of the unit.

\section{CHP Costs}

As outlined earlier, the model compares the cost of a CHP plant versus purchasing the power on the open market from the utilities perspective. It accomplishes this by comparing both the fixed and variable costs to market futures. CHP variable costs consists of two components, fuel cost in (\$/MWh) and Maintenance Costs (\$/MWh).

Where

$$
V C_{C H P}=\frac{(H R \times N G)}{1,000}+M C_{C H P}(1)
$$

$$
V C_{C H P} \text { is the Variable cost for CHP in } \frac{\$}{\mathrm{MWh}}
$$

$H R$ is the Heat Rate for CHP at Rated Net Output in $\frac{\mathrm{Btu}}{\mathrm{kWh}}$

$N G$ is the monthly natural gas price in $\$ / \mathrm{mmBtu}$

$M C_{C H P}$ is the CHP Maintenace Costs in $\$ / \mathrm{MWh}$

The division by 1,000 is to change the heat rate from $\mathrm{Btu} / \mathrm{kWh}$ to MMBtu/MWh

The $H R$, and $M C_{C H P}$ where taken from the Catalog of $C H P$ Technologies[4]in order to maintain similar assumptions behind the numbers.

\section{E. Market Costs}

The based off of assumption 7, the model allows the user to select whether the unit operates during first, second, and/or third shift; additionally the user can select if these shifts extend into the week. Using these inputs, and the number of week days in a month, the model determines the number of On-Peak and Off-Peak Operating hours.

$$
\begin{aligned}
O N P_{\text {Hours }}=W D_{\text {Mont } h} \\
\times(\text { First shift } * 8+\text { Second Shift } \times 8)(2) \\
\text { OFFP } P_{\text {Hours }}=W D_{\text {Mont } h} \times(\text { Third Shift } * 8)+W E_{\text {Mont } h} \\
\quad \times \text { Weekend Shifts } \\
\quad \times(\text { First shift } \times 8+\text { Second Shift } \times 8 \\
\quad+\text { Third shift } \times 8)
\end{aligned}
$$

Where

$$
\begin{aligned}
& O N P_{\text {Hours }}=\text { On Peak Hours } \\
& \text { OFFP }_{\text {Hours }}=\text { Off Peak Hours }
\end{aligned}
$$

$W D_{\text {Mont } h}=$ Working Days (Mon. to Fridays)in the month $W E_{\text {Mont } h}=$ Weekend Days (Sat. to Sundays)in the month First shift

$=$ Whether the CHP runs during the first shift. value of 1 or 0 Second shift

$=$ Whether the CHP runs during the 2 nd shift. value of 1 or 0
Third shift

$=$ Whether the CHP runs during the 3rd shift. value of 1 or 0 Weekend shifts

$=$ Whether the CHP runs during the weekend. value of 1 or $01_{1}$

Using equations 1 and 3 , the model calculates the monthly cost of CHP power produced during peak hours; the model calculates monthly off peak production costs with equations 1 and 4.

$$
\begin{aligned}
& \text { CHP Production Cost } \text { On Peak } \\
& =V C_{\text {CHP }} \times O N P_{\text {Hours }} \times \text { Net Output }
\end{aligned}
$$

$$
\begin{aligned}
\text { CHPProductionCost }_{\text {OffPeak }} & \\
& =V C_{\text {CHP }} \times \text { OFFP }_{\text {Hours }} \\
& \times \text { NetOutput }
\end{aligned}
$$

Where Net Output is the net output of the unit in MW at ISO rated conditions.

As mentioned earlier, the model uses OTC Holding energy forwards for Day Ahead energy prices at hub points in different power markets. These prices, referred to as $\mathrm{EP}_{\text {Market }}$ represent the expected price of power for On Peak and Off Peak power respectively.As one option, utilities participating in these markets could purchase the power off of the market at these points to supply to their customers. The model calculates the equivalent market cost of the CHP produced power. Market Energy Cost On Peak $=E P_{\text {Market }, \text { On Peak }} \times$ ONP $P_{\text {Hours }} \times$ Net Output (6)

$$
\begin{aligned}
& \text { 『Market Energy Cost》_(Off Peak) } \\
& =\nabla E P \nabla_{-} \text {(Market, Off Peak) } \\
& \times \triangle O F F P \rrbracket_{-} \text {Hours } \times \text { Net Output (7) }
\end{aligned}
$$

Finally, the waste heat revenue completes the final part of the variable operating costs. Using the Total Heat Recovered numbers from Catalog of CHP Technologies and a cost multiplier, the model calculates the monthly value of the waste heat. Using assumption 8 and 9:

$$
\begin{gathered}
W H_{\text {sold }}=W H G \times O N P_{\text {Hours }} \times O F F P_{\text {Hours }} \\
W H_{\text {revenue }}=W H_{\text {sold }} \times N G \times C W H(\%)
\end{gathered}
$$

Where

$W H_{\text {sold }}=$ Waste Heat sold in $\mathrm{mmBtu} / \mathrm{hr}$ $W H G=$ Waste Heat Generated in $\mathrm{mmBtu} / \mathrm{hr}$ $N G_{\text {Mont hly }}=$ Futures price of Natural Gas in $\frac{\$}{\mathrm{mmBtu}}(\mathrm{HHV})$ $C W H(\%)=$ Cost of Waste Heat as a precentage of $\mathrm{NG}_{\text {Monthly }}$ $W H_{\text {revenue }}=$ Monthly Revenue of Waste Heat Sold

\section{F. Overall Monthly Variable Costs}

Finally the model compares the cost of purchasing the power off of the market to CHP production:

\footnotetext{
${ }^{1}$ The weekend shift assumes that the First, Second, and Third shifts would continue into the whole weekend for simplicity.
} 
MVC $=$ CHP Production Cost $_{\text {On Peak }}$

+ CHP Production Cost Off Peak $+W H_{\text {revenue }}$

- (Market Energy Cost On Peak

+ Market Energy Cost Off Peak $_{\text {) }}$

Where

$M V C=$ Monthly Variable Cost. A positive number means that the CHP system saved money compare to purchasing power off of the market and a negative number means that a $\mathrm{CHP}$ system lost money.

Finally the model sums up the MVC by year to produce a yearly overview of the variable costs and the fixed costs.

\section{G. Fixed Costs}

Installation values provided in Catalog of CHP Technologies for the installation cost of a new CHP plant. These numbers can vary due to site location, labor laws, material prices, and many other factors. By using the numbers provided in Catalog of CHP Technologies, it provides an equal footing for the model to compare. The model calculates a simple loan payback as if it were a mortgage. The model takes in from the user both the term and the interest rate and produces an annualized payment. The market equivalent of this cost would be capacity payment. As mentioned earlier, capacity payments and methods vary greatly from one market to the next. This model assumes that the PJM ones are indicative of the next five years and that $\$ 150 / \mathrm{MW}$ will persist after that. The model calculatesthe capacity as

$$
\begin{array}{r}
M C_{\text {Annual }}=\text { Capacity Price } \times \text { Net Output } \\
\times 365^{\text {days }} / \text { Year }
\end{array}
$$

Where

$$
\begin{gathered}
M C_{\text {Annual }}=\text { AnnualMarket Value of the Capacity } \\
\text { Capacity Price = Capacity Price in MW - day }
\end{gathered}
$$

Fixed costs for the engine were calculated by financing, at fixed percentage rate, the upfront capital cost over an adjustable period of time and adding on any necessary other fixed costs, which are labor, insurance, property taxes, and emission testing.

The financing cost were calculated using Excel's PMT function which calculates a simple loan payment.

$$
F C_{C H P}=\frac{I C \times R \times(1+R)^{N}}{(1+R)^{N}}+\sum \text { Annual Costs }
$$

Where

$F C_{C H P}$ is the annual fixed of miantianing and finnacing the CHP

$I C$ is the upfront installation costs for the CHP, taken from Catalog of CHP Technologies

$R$ is the annaul interest rate

$N$ is the term of the loan in years

Annual costs are an estimate of expected yearly costs, including property taxes, insurance, additional utility employees, and emission testing.

The margin for the CHP compared to the market is calculated as:

Where

$$
M F C=M C_{\text {Annual }}-F C_{C H P}
$$

MFC = Annual Marginal Fixed Cost. A Positive number indicates that the CHP is a savings over purchasing capacity on the market. A Negative number indicates that the CHP is a loss over purchasing capacity on the market.

\section{H. Annual Total Costs}

The model looks at the total production CHP costs, total CHP fixed costs, waste heat revenue, market energy costs, and market capacity costs to determine on annual basis whether the plant was a positive or negative investment. The margin is then compared to total production CHP costs and total CHP fixe costs to calculate a yearly return on expenditures.

Where

$$
T M C_{\text {Annual }}=\sum_{\text {Year }} M V C+M F C
$$

$$
T M C_{\text {Annual }}=\text { Annual Total Marginal Cost }
$$

$$
\begin{aligned}
& \text { Yearly Return } \\
& =\frac{T M C_{\text {Annual }}}{F C_{\text {CHP }}+\sum_{\text {annaul }} \text { CHP Production Cost } \text { On Peak }+ \text { Off Peak }_{\text {P }}}
\end{aligned}
$$

\section{Selectable Options}

The model has ten selectable options that can many different results. Table 2 shows the user interface and below are the list of selectable options:

1. Engine: Allows the selection of one of the ten CHP systems listed in table 1 .

2. Shift 1 Operation:True means 6:00AM-2:00PM, M-F, in market time. False signals the unit is offline.

3. Shift 2 Operation:True means 2:00PM-8:00PM, M-F, in market time. False signals the unit is offline.

4. Shift 3 Operation:True means 8:00PM-6:00AM, M-F, in market time. False signals the unit is offline.

5. Weekends: True extends Shifts 1, 2, and 3 into Saturday and Sunday.

6. Interest Rate: Interest rate which the utility finances the CHP Plant. Rate must be between 0\%-100\%

7. Term: The length of the financing for the CHP Plant.

8. Power Hub: Allows the user to select one of seven power hubs via a drop down menu. This selection will automatically change the model to use to proper on-peak, off-peak, and gas prices

9. Cost of Waste Heat: This is the percentage of the natural gas price the waste heat is sold for.

10. Property Tax Rate: This is the property tax rate that the CHP plant will be taxed at.

\section{J. Outputs}

Using the previous assumptions, inputs and equations, the model provides six tables summarizing the next six years of operation. These tables are intended to provider a concise method in which to compare the advantages and disadvantages of a CHP plant. Additionally, through the use of multiple tables the user is able to pinpoint which areas are contributing to positive or negative margins. With the numbers being on a Wartsilia 20V34SG built in the AEPDayton Hub area. All of the selected options are shown in table 2. 
The "Production Information" table (table 3) highlights the amount of electricity (MWhs) and waste heat (MMBtu) generated for each year. These calculations are based on the shift operations selected above. Off Peak energy is zero due to neither the weekend shift nor third shift being selected.Production costs include the annual variable production costs associated with the CHP plant (fuel and variable maintenance cost), the cost if the equivalent power was purchased off of the market, and revenue brought in from waste heat sales.

End user savings (table 4) is the estimated annual savings that the industrial end user would realize due to the CHP plant. It is a comparison of the using waste heat in place of natural gas. Total costs is given in table (5) for the model, presenting whether the CHP plant will be an. annual net savings or loss. The total margin is divided by the total annual CHP costs to compute a yearly return on the money spent for the year.

\section{RESULTS:}

The model allows the comparisons of ten different CHP power systems at different hubs. With access to SNL.com, or asimilar futures service, all of the hubs are accessible. With the model sent out to users without access, the model is limited to seven hubs. For analysis, the model will use seven different hubs in five different markets, as listed in
Table6. Since this paper focused on the development of a model, and all of the possible results, one engine, Wartsilia's 20V34SG engine, is reviewed in detailed.

Wartsilia's 20V34SG is a Finish engine manufacturer building reciprocating internal combustion engines for ship power, gas compression, and power generation. [9].

As with most reciprocating engines, their units have high thermal efficiency; on larger engines it can reach up to $49 \%$ (LHV). One of their most popular products for power generation is the $20 \mathrm{~V} 34 \mathrm{SG}$, with a net output of $9,341 \mathrm{~kW}$. U.S. EPA Catalog of CHP Technologies, the 20V34SG was the largest reciprocating engine, as well the CHP with the lowest (most efficient) electrical heat rate at 8,207 Btu/kWh and the lowest maintenance cost at $\$ 8.50 / \mathrm{MWh}$ [4]. Since variable cost margin is determined by the heat rate and the variable maintenance costs compared to the market cost, this low heat rate and maintenance cost allowed it to be one of the most competitive CHP plants. Even with its low variable costs, low maintenance costs, and low capital costs (in $\$ / \mathrm{kW}$ ), a Wartsilia 20V34SG CHP plant would not be a good investment for an utility company operating in PJM's AEP-Dayton area, due to the annual return ranging between $-19.4 \%$ and $-7.1 \%$ and a six year total return of $-20 \%$. [10]. When looking at other areas, the economics differ significantly, as shown in table 7 .

TABLE 2

Table 2. Wartsilia 20V34G assumptions for unit deployed in AEP-Dayton Hub

\begin{tabular}{|c|c|c|c|}
\hline \multicolumn{4}{|c|}{ CHP Plant Selection } \\
\hline Engine & \multicolumn{2}{|c|}{ Wartsilia 20V34SG } & $\Delta$ \\
\hline Net Output (MW) & 9.341 & & $\checkmark$ \\
\hline $\begin{array}{c}\text { Top Heat Rate } \\
\text { Btu/kWh }\end{array}$ & 8,207 & $\begin{array}{l}\text { Fuel Burned } \\
\mathrm{mmBtu} / \mathrm{hr}\end{array}$ & 69.7 \\
\hline $\begin{array}{c}\text { Variable } \\
\text { Maintenance Cost } \\
\text { (\$/MWh) }\end{array}$ & 8.50 & $\begin{array}{c}\text { Total Waste Heat } \\
\text { Generated } \\
\mathrm{mmBtu} / \mathrm{hr}\end{array}$ & 26.81 \\
\hline Yearly Fixed Costs & $(200,785)$ & CHP CO & ital Cost \\
\hline \multicolumn{2}{|c|}{ End User Operation } & Install Cost \$/kW & $1,433.00$ \\
\hline Shift 1 Operation & TRUE & Total Install Cost & $13,385,653$ \\
\hline Shift 2 Operation & TRUE & Interest Rate & $5 \%$ \\
\hline Shift 3 Operation & FALSE & Term & 25 \\
\hline Weekends & FALSE & Annual Payment & $(\$ 949,744.97)$ \\
\hline
\end{tabular}

\begin{tabular}{|c|c|c|}
\hline Power HUB & AEP-DAYTON HUB & <-- Select Power Market \\
\hline Btu/kWh & 3412 & \\
\hline Electric Efficiency & $42 \%$ & \\
\hline $\begin{array}{c}\text { Sellable Energy } \\
\text { (mmBtu/hr) }\end{array}$ & 26.81 & \\
\hline $\begin{array}{c}\text { Cost of Waste Heat } \\
\text { (\% of Natural Gas } \\
\text { Cost) }\end{array}$ & $50 \%$ & $\begin{array}{l}<-- \text { Select \% of Natural Gas Heat ( } \mathrm{mmBtu} / \mathrm{hr} \text { ) } \\
\text { is sold }\end{array}$ \\
\hline Property Tax Rate & $1.50 \%$ & <-- Select Appropriate Property Tax Rate \\
\hline
\end{tabular}


TABLE 3

Production information for model run based off of table (1) assumptions.

\begin{tabular}{|c|c|c|c|c|}
\hline \multicolumn{5}{|c|}{ Production Information } \\
\hline Year & $\begin{array}{c}\text { Total On Peak } \\
\text { MWh }\end{array}$ & Total Off Peak MWh & Total MWh Produced & $\begin{array}{c}\text { Total Waste Heat } \\
\text { (mmBtu) }\end{array}$ \\
\hline 2015 & 40,204 & 0 & 40,204 & 115,390 \\
\hline 2016 & 40,353 & 0 & 40,353 & 115,819 \\
\hline 2017 & 40,204 & 0 & 40,204 & 115,390 \\
\hline 2018 & 40,204 & 0 & 40,204 & 115,390 \\
\hline 2019 & 40,353 & 0 & 40,353 & 115,819 \\
\hline 2020 & 40,353 & 0 & 40,353 & 115,819 \\
\hline
\end{tabular}

\section{DISCUSSION}

The economics for the plant are driven by two factors. With variable cost, the implied heat rate (the price of power divided by the cost of gas) determines whether a unit will be economical.Figs. 1 and 2 give a good indication of where a CHP plant heat rate would need to be for the unit to be lower cost than market power. To account for maintenance cost, the maintenance cost adder per hour can be divided by the predicted gas cost and converted in Btu/kWh heat rate adder.
TABLE 4

End user savings based off of the model assumptions inTable 2

\begin{tabular}{|c|cc|}
\hline \multicolumn{2}{|c|}{ End-user Savings } \\
\hline Year & \multicolumn{2}{|c|}{ Enduser Savings } \\
\hline 2015 & $\$$ & $203,272.78$ \\
\hline 2016 & $\$$ & $201,574.27$ \\
\hline 2017 & $\$$ & $207,841.35$ \\
\hline 2018 & $\$$ & $214,304.86$ \\
\hline 2019 & $\$$ & $222,787.58$ \\
\hline 2020 & $\$$ & $230,821.85$ \\
\hline
\end{tabular}

TABLE 5

Total Costs complies the total margin and total annual costs to show return (or loss) on annual money spent

\begin{tabular}{|c|c|c|c|c|c|c|c|c|c|c|c|}
\hline \multicolumn{12}{|c|}{ Total Cost } \\
\hline Year & & Cost Margin & Var & Cost Margin & & Margin & & duction Cost & Annual Payment & Total CHP Costs & Yearly Return \\
\hline 2015 & $\$$ & $(1,060,830.73)$ & $\$$ & $497,660.80$ & $\$$ & $1563,169.93$ & $\$$ & $1,504,223.77$ & $\$ 1,289,604.43$ & $\$ 2,793,828.20$ & $-20.2 \%$ \\
\hline 2016 & $\$$ & $(1,026,701.99)$ & $\$$ & $486,595.48$ & $\$$ & $(540,106.5)$ & $\$$ & $1,507,086.25$ & $\$ 1,289,604.43$ & $\$ 2,796,690.69$ & $-19.3 \%$ \\
\hline 2017 & $\$$ & $(1,287,969.29)$ & $\$$ & $464,478.61$ & $\$$ & $1823,490.68$ & $\$$ & $1,539,683.37$ & $\$ 1,289,604.43$ & $\$ 2,829,287.80$ & $-29.1 \%$ \\
\hline 2018 & $\$$ & $(978,969.48)$ & $\$$ & $455,475.49$ & $\$$ & $1523,493.98$ & $\$$ & $1,577,408.48$ & $\$ 1,289,604.43$ & $\$ 2,867,012.91$ & $-18.3 \%$ \\
\hline 2019 & $\$$ & $(978,969.48)$ & $\$$ & $456,553.99$ & $\$$ & $1522,415.48$ & $\$$ & $1,625,789.05$ & $\$ 1,289,604.43$ & $\$ 2,915,393.48$ & $-17.9 \%$ \\
\hline 2020 & $\$$ & $(978,969.48)$ & $\$$ & $451,789.21$ & $\$$ & $1527,180.26$ & $\$$ & $1,679,787.15$ & $\$ 1,289,604.43$ & $\$ 2,969,391.58$ & $-17.8 \%$ \\
\hline
\end{tabular}

TABLE 6

Hub Price Points, Markets, and Gas Points Used for this Paper

\begin{tabular}{|c|c|c|c|}
\hline Power Point Hub & Energy Market & Gas Point & Approximate Local \\
\hline NDIANA.HUB & MISO & Chicag0 & Indianapolis, $\mathbb{N}$ \\
\hline AEP-DAYTON HUB & PJM & Lebanon Hub & Columbus, OH \\
\hline NLLLNOIS HUB & PJM & Chicag0 & Chicago, $\mathrm{L}$ \\
\hline PSEG & PJM & Transco Zone 6 Non-NY & Newark, NJ \\
\hline Hudson Valley-G & NYISO & Transco Zone 6 NY & Hudson Valley, NY \\
\hline .Z.NEMASSBOST & NEISO & Algon Gates & Boston, MA \\
\hline NP15 & CAISO & PG\&E Gate & San Francisco, CA \\
\hline
\end{tabular}

Average monthly heat rates over the six year period from 2015-2021 for both On-peak and Off-peak in the seven different hub points (five different markets) are shown.These two charts showthe fluctuation of implied heat rate throughout the year and the difference between on peak and off peak rates. On peak rates are higher and are determined mainly by prevailing weather patterns in the area. Off peak implied heat rates do not closely follow the weather, being driven mainly by base load, and vary greatly from hub to hub. These conditions mean two things for the model. First, onpeak operation (running first and second shift) is generally beneficial for the economics of a CHP plant. As a corollary, off peak generation is generally economically unfavorable. When operating off peak, the costs of the CHP plant generally had a lower return, in both whole dollars and percentage, then when just operating during On-peak times. The lower whole dollarswas due to the unit operating at a marginal loss during off peak times. With comparing just variable costs, the model normally returned a positive margin for On-peak operations, and intermittently on Off-Peak power. This is due to the generally favorable heat rates, especially on the larger (greater than $1 \mathrm{MW}$ ) reciprocating units. What has the largest effect on utility ownership of CHP plants and returns is the fixed cost recovery.

Fixed costs for a CHP plant compose a very large part of the annual operations, covering debt service, annual maintenance, property taxes, and needed salaries. Due to the nature of the energy market, being based on the marginal power costs, the energy market itself is unlikely sufficient to cover the fixed costs. This leads to the need to recover these costs in other methods, which can be rate basis, or market purchases. 
Fixed cost recovery for utilities depends on the state and utility structure. In regulated states, Utilities are able to recover their fixed costs, through their rate base with their customers. This method normally includes a return on equity investments, and would make CHP plant investment very favorable. For example, a utility may be able earn a margin of $10 \%$ on its annual fixed costs. This process normally involves going in front of the state utility commission and receiving a certificate of necessity before building a power plant. A CHP plant could be a creative way to address the need for additional generation, with potential for reduction in emissions. Even in regulated states, if there is a market for capacity, comparisons will still be made between the market value of capacity and the priced pay for by the utility.

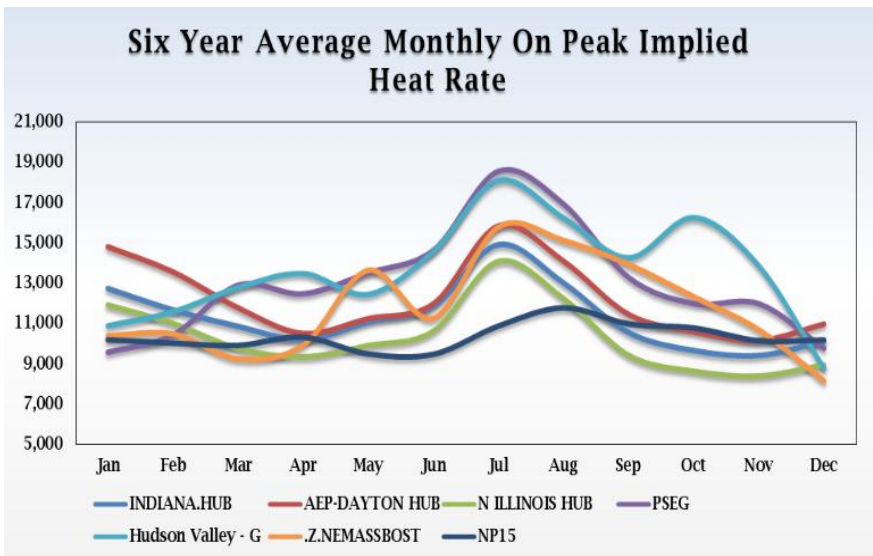

Fig. 1: Six Year Monthly Average On Peak Implied Heat Rate

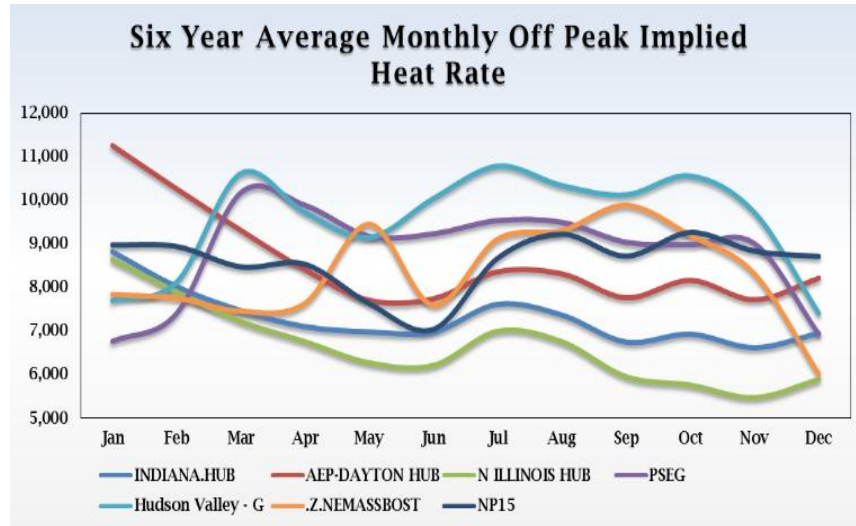

Fig. 2: Six Year Monthly Average Off Peak Implied Heat Rate

TABLE 7

Six year total costs for the Wartsilia 20V34G at seven different hub points

Six Year (2015-2020) Total Cost

\begin{tabular}{|c|c|c|c|c|c|c|c|c|c|c|}
\hline \multicolumn{11}{|c|}{ Six Year (2015-2020) Total Cost } \\
\hline Six Year Total & & $\mathrm{d}$ Cost Margin & & e Cost Margin & Total Margin & & HP Production Cost & Annual Payment & \begin{tabular}{|l|} 
Total CHPCosts \\
\end{tabular} & Six Year Average Return \\
\hline INDIANA.HUB & $\$$ & $(6,560,527.37)$ & $\$$ & $2,441,449.85$ & $\$(4,119,077.52)$ & $\$$ & $10,184,926.65$ & $\$ 5,698,469.84$ & $\$ 15,883,396.48$ & $-26 \%$ \\
\hline AEP-DAYTONHUB & $\$$ & $(4,600,528.23)$ & $\$$ & $2,812,553.58$ & $\$(1,787,974.65)$ & $\$$ & $9,433,978.07$ & $\$ 5,698,469.84$ & $\$ 15,132,447.91$ & $-12 \%$ \\
\hline NILLINOIS HUB & $\$$ & $(4,600,528.23)$ & $\$$ & $1,422,461.83$ & $\$(3,178,066.40)$ & $\$$ & $10,184,926.65$ & $\$ \quad 5,698,469.84$ & $\$ 15,883,396.48$ & $-20 \%$ \\
\hline PSEG & $\$$ & $(4,600,528.23)$ & $\$$ & $3,744,660.46$ & $\$(855,867.77)$ & $\$$ & $10,712,921.25$ & $\$ \quad 5,698,469.84$ & $\$ 16,411,391.08$ & $-5 \%$ \\
\hline Hudson Valley - $G$ & $\$$ & $3,575,568.54$ & $\$$ & $4,754,382.50$ & $\$ 8,329,951.04$ & $\$$ & $11,603,470.57$ & $\$ 5,698,469.84$ & $\$ 17,301,940.40$ & $48 \%$ \\
\hline Z.NEMASSBOST & $\$$ & $(1,204,026.99)$ & $\$$ & $4,496,709.91$ & $\$ 3,292,682.92$ & $\$$ & $15,179,057,02$ & $\$ \quad 5,698,469.84$ & $\$ 20,877,526.85$ & $15.8 \%$ \\
\hline NP15 & $\$$ & $(6.903 .178 .61)$ & $\$$ & 1.995 .871 .55 & $\$(4.907 .307 .06)$ & , & 11.424 .234 .67 & \$ 5.698.469.84 & \$ 17.122.704.51 & $-28.7 \%$ \\
\hline
\end{tabular}

Another method of recovery for utilities, especially in deregulated states, is to purchase capacity either through contracts or capacity markets. The presented model used capacity markets, as they provided a baseline for the costs and reflected the situation in each market. That being said, the capacity markets costs, structure, and variably differ greatly from market to market. CAISO and ECORT do not have a capacity market, MISO has a two year old one, and PJM, NYISO, and NEISO have older more established markets. None of these markets have a stable capacity market, nor longer than a three year outlook. For this model, the capacity prices were enter for what was already known, and then averaged of the last three years for future unknown years as an approximation. The markets with the best return were NYISO Hudson Valley and NEISO Boston Hub, both of which had high capacity prices.
The presented model currently has the capacity prices incorporated for the markets, and prices for rate base recovery could easy be calculated and added in. In general, the prices in MW-day would need to be above \$200 MW-day for the CHP plant to be a good investment for the utility.

\section{CONCLUSION}

The present model provides a useful tool for utility to determine whether investment in a CHP Plant should warrant further detailed investigation. The model allows a utility to compare the future cost of power to the overall costs of investment in a CHP plant is a quick and efficient fashion. In general, from the results attained, Outside of New England and New York region, utilities would probably not further investigate CHP plant investments due to low potential returns. 
This model could be improved in a few ways. First, incorporation of temperature effects on CHP output throughout the year. This could be accomplished by using know derating factors and average day and night temperatures. Second, the forward estimates could be taken out an additional years. Currently, the forwards only look seven years into the future, which is generally shorter than the life of a CHP plant. Third, adding additional automation to run the returns based on probability outcomes of future power and gas prices.

\section{REFERENCES}

[1] C. B. Olant, "Oak Ridge National Laboaratory: Guide to Combined Heat and Power Systems for Boiler Owners and Operators," $30 \quad$ July $2004 . \quad$ [Online]. http://www1.eere.energy.gov/manufacturing/tech_assistance/ pdfs/guide_chp_boiler.pdf. [Accessed 14 December 2014].

[2] A. F. I. Lange, "Voluntary Progarms to Encourage Diffusion: The Case of the Combined HEat-and PowerPartnership," The Energy Journal, vol. 35, no. 1, 2014.

[3] U.S. Energy Information Administration, "Repeal of the Powerplant and Industrial Fuel Use Act (1987)," [Online]. http://www.eia.gov/oil_gas/natural_gas/analysis_publications /ngmajorleg/repeal.html. [Accessed 2110 2014].

[4] U.S. EPA CHP: Combined Heat and Power Partnership, "Catalog of CHP Technologies," Sept. 2014. [Online]http://www.epa.gov/chp/documents/catalog_chptech _full.pdf..

[5] Internal Revenue Service, "www.IRS.gov," 2013. [Online]. Available: http://www.irs.gov/pub/irs-pdf/p946.pdf. [Accessed 14 12 2014].

[6] T. Gou, M. I. Henwood and M. van Oojien, "An Algorithim for Combined Heat and Power Economic Dispatch," IEEE Transactions on Power System, Vol 11, No. 4, pp. 1778-1784, November 1996.

[7] PJM, "ERPM User Guide," 12 September 2012. [Online]. Available: http://www.pjm.com/markets-andoperations/rpm.aspx.[Accessed 6 Dec. 2014].

[8] Midcontiential Independent System Operator, "DayAhead Pricing Report Readers' Guide," 19 Decemeber 2013. [Online].

https://www.misoenergy.org/Library/Repository/Report/Read ers\%20Guide/Day-

Ahead\%20Pricing\%20Report\%20Readers\%20Guide.pdf.

[Accessed 12 Oct. 2014].

[9] Wartsila, "Company Management," Wartsila, 2014. [Online]. http://www.wartsila.com/en/about/companymanagement/overview [Accessed 7 Nov. 2014].

[10] S. M. Harvey, "CAISO," California ISO, 9 October 2007. [Online]. http://www.caiso.com/Documents/SummaryNewEngland.pdf. [Accessed 9 Nov. 2014].

\section{BIOGRAPHIES}

M. Malguarnera is currently working for Indiana Municipal utility. He received the B.S. in mechanical engineering from Case Western University and a MS from Purdue University, Indianapolis, in 2014.

A. Razban is currently Assistant Director of the Industrial Assessment Center (IAC) (sponsored by DOE) and a faculty in the Mechanical Engineering Department at IUPUI. He received his $\mathrm{Ph} . \mathrm{D}$. in Robotics and Automation from Imperial College, London, UK in 1994, and the MSE in Electrical engineering from University of Michigan, Ann Arbor, MI in 1991. Dr. Razban has over 15 years of industrial experience in energy management, medical device, electronics and automotive industry. He has been with the Mechanical Engineering department, Purdue School of Engineering and Technology, Indianapolis since fall 2010 